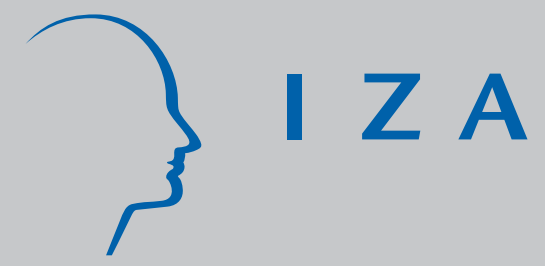

IZA DP No. 4217

The Flexibility of the Workweek in the United States:

Evidence from the FIFA World Cup

Fernando A. Lozano

June 2009 


\title{
The Flexibility of the Workweek in the United States: Evidence from the FIFA World Cup
}

\author{
Fernando A. Lozano \\ Pomona College, \\ University of Michigan and IZA
}

Discussion Paper No. 4217
June 2009

IZA
P.O. Box 7240
53072 Bonn
Germany

\author{
Phone: +49-228-3894-0 \\ Fax: +49-228-3894-180 \\ E-mail: iza@iza.org
}

\begin{abstract}
Any opinions expressed here are those of the author(s) and not those of IZA. Research published in this series may include views on policy, but the institute itself takes no institutional policy positions.

The Institute for the Study of Labor (IZA) in Bonn is a local and virtual international research center and a place of communication between science, politics and business. IZA is an independent nonprofit organization supported by Deutsche Post Foundation. The center is associated with the University of Bonn and offers a stimulating research environment through its international network, workshops and conferences, data service, project support, research visits and doctoral program. IZA engages in (i) original and internationally competitive research in all fields of labor economics, (ii) development of policy concepts, and (iii) dissemination of research results and concepts to the interested public.
\end{abstract}

IZA Discussion Papers often represent preliminary work and are circulated to encourage discussion. Citation of such a paper should account for its provisional character. A revised version may be available directly from the author. 


\section{ABSTRACT \\ The Flexibility of the Workweek in the United States: Evidence from the FIFA World Cup*}

In this paper I explore the flexibility of the work week in the United States, using the FIFA Soccer World Cup as a natural experiment. My empirical strategy exploits the exogenous variation that arises due to which country hosts the World Cup, as this will determine the time games are broadcast across different time zones in the United States. The hour of the day when games are broadcast differentially affects hours of work across different time zones. Further, the calendar timing of the World Cup allows me to compare labor market outcomes in June/July for a worker in World Cup year $t$, with the outcomes in June/July for a worker in non-World Cup years $t+1, t+2$ and $t+3$. My results highlight the importance of the worker's pay frequency in their work week flexibility, as all differences in hours of work due to the World Cup are concentrated among salary paid workers, while hourly paid workers do not change their market hours during the World Cup. Also, my results show that after controlling for observable demographic characteristics as well as year and month fixed effects, a worker reduces on average his weekly number of hours of work during the World Cup by statistically significant estimates that range from 9 weekly minutes to 28 weekly minutes, depending on specification choice and time of the day during which World Cup games are broadcast live in the U.S.

JEL Classification: J22, L83

Keywords: $\quad$ schedule flexibility, hours of work, FIFA World Cup

Corresponding author:

Fernando A. Lozano

Pomona College

425 N. College Avenue

Claremont, CA 91711

USA

E-mail: fernando.lozano@pomona.edu

\footnotetext{
* I am grateful to Charlie Brown, Sheldon Danziger, Dan Hamermesh, Peter Kuhn, Greg Price and Michael Steinberger for their comments and suggestions, to seminar participants at UC Riverside, The University of Michigan Ann Arbor, The University of Wisconsin Madison, Duke University, San Diego State University, SUNY Stony Brook and to participants in the 2008 Meetings of the Society of Labor Economics, the 2008 DITE Conference in Santa Barbara, CA and the 2008 European Association of Labor Economics Meetings. This research was supported in part by a grant from the Ford Foundation to the Research and Training Program on Poverty and Public Policy at the University of Michigan. All errors remain mine.
} 


\section{Introduction}

At any given time, workers should benefit from some flexibility in their work schedule. There are events whose timing overlap with the workday and rescheduling work, or abstaining from work, to consume a given event may result in higher workers' utility. Perhaps workers know ahead of time when this event will occur and plan accordingly: for example during the NCAA tournaments in March, Saint Patrick's Day also in March, or the Presidential Inauguration in January. Similarly, workers will equally benefit from some work flexibility in the face of an event that is unpredictable, such as: bad weather, a natural disaster, or a sick child at home. Even though schedule flexibility is important and valued by workers, we know very little about its prevalence in the United States.

While workers' schedule flexibility has remained relatively unexplored, economists have paid considerable attention to the market hours of American workers. For example, Costa (2000) analyzes the evolution of the workday length of the average American male between 1890 and 1991, Coleman and Pencavel (1993a, 1993b) analyze the evolution of hours worked by American workers between 1940-1988, and Kuhn and Lozano (2008) analyze the evolution of the length of the workweek of American workers between 1979 and 2006. Similarly, economists have been interested in understanding the tradeoff between leisure and paid labor. Recent research includes Connolly (2008) who shows that weather determines a workers allocation of market hours, as workers work longer hours during rainy days than on sunny days, or Gonzalez-Chapela (2007) who show that as prices of recreation goods (complements of leisure) increase, American workers' hours of work increase as well. A natural 
extension to ask is whether workers would decrease their hours of labor in the face of an event that overlaps with the workday. If workers value such an event enough, then it is conceivable that they would choose to consume the event rather than do paid market work when the event is occurring.

In this paper, I use the exogenous variation that arises due to the FIFA soccer World Cup to explore the schedule flexibility of American workers during the last 15 years, . That is, unlike events that cater to the American public and may be scheduled at times where Americans reduce their work hours anyway, the World Cup's games schedule and host country choice is determined mostly independently form the U.S. labor market or the preferences of American workers. Further, as each World Cup is hosted by a different country and played every four years, the time games are broadcast live in America may or may not overlap with the workday depending on the host country where the World Cup is played. This allows me to estimate the causal effect that the World Cup has on changes in a worker's schedule flexibility from three independent sources of variation: across time - comparing year $t$ with year $t+i, i=1,2,3$; across space - the host country will determine the time games are broadcast live in the U.S.; lastly, the third source of variation is the time games are broadcast live in each U.S. time zone, as each match broadcast's scheduled time will differ across different time zones - potentially the same game will overlap with the workday in a time zone within the U.S. and not in other time zones.

Empirically, I compare deviations in a worker's weekly work hours during the World Cup from his usual work schedule, with the deviations from the usual workweek of a demographically equivalent worker at other times. Importantly, and as argued above, games played in different countries are televised live at different local times, and the 
times that these games are televised locally will determine whether the timing of the World Cup overlaps with the workers regular work schedule in each U.S. time zone. For example, in France 1998 most of the games were played at 9:00 pm Central European Time; which is 4:00 pm on the U.S. East Coast and 1:00 pm on the Pacific Coast. In contrast, in Korea-Japan 2002 most of the games took place at 8:30 pm Eastern Asia time, this is 7:30 am on the East Coast and 4:30 am on the West Coast. I hypothesize that as the World Cup is played in different host countries, the worker's decision to supply less market hours than in a usual work week varies accordingly to the time games are televised in the local time zone: when the games are televised early in the morning or late in the afternoon, Americans will not reduce their hours of work as much as when games are televised between 9:00 am and 5:00 pm locally. In a sense, my strategy is similar to Hamermesh et al (2008) who analyze the timing and coordination between persons' activities and local television schedules.

My results show that after controlling for observable demographic characteristics, as well as year and monthly fixed effects, American workers reduce their weekly hours of work on average during the World Cup by up to 9 minutes or roughly one out of every ten workers reduces his weekly hours by the time it takes to watch a complete soccer match (90 minutes plus fifteen minutes half time intermission) per week. Most of this change is concentrated among salary paid workers, who reduce their hours of work by 28 weekly minutes on average. Again, this is equivalent to one in three salary paid workers adjusting his hours of work by the time it takes to watch a game, or more likely 1 in 9 salary paid workers adjusts his hours of work by the amount of time it takes to watch three weekly soccer matches. Interestingly, after controlling for demographic characteristics, year and month fixed effects, hourly paid workers 
do not adjust their hours of work during the soccer World Cup. This difference is significant because the short run opportunity cost of one hour worked less among salary paid workers is arguably zero or very small, while for hourly paid workers the short run opportunity cost of one hour less of work is the forgone hourly wage. To the extent that salary paid workers are associated with white collar jobs, and hourly paid workers are associated with blue collar jobs (Hamermesh, 2002), this result highlights an important source in labor market differences among workers in the United States with different pay frequency.

\section{Data}

In this paper I use data from the 1994-2007 NBER Collection of the Current Population Survey Outgoing Rotations Groups (CPS OGR). In order to identify variations in hours of work between households that are surveyed during the World Cup and not, I estimate the difference between the respondent's hours worked last week and his usual hours of work, and I multiply this difference by 60 for ease of interpretation $^{1}$. These two measures are consistent as they refer to the hours of work in the respondent's main job, and the only difference is that usual hours refers to the mode of all workweeks, and last week refers to the hours in the week prior to the CPS survey week, the reference week. ${ }^{2}$. A negative difference between last week hours and usual

\footnotetext{
${ }^{1}$ Multiplying by 60 allows the results to be interpreted in minutes, instead than in fraction of an hour.

${ }^{2}$ The question for usual hours is HRUSL1: How many hours per week (do/does) (name/you) USUALLY work at (your/his/her) (job?/main job? By main job we mean) (the one at which (you/he/she) usually) ((work/works) the most hours.) and the question for hours last week is HRACT1: ((LAST WEEK/THE WEEK BEFORE LAST)/So, for (LAST WEEK/THE WEEK BEFORE LAST)), how many hours did (you/he/she) ACTUALLY work at (your/his/her) (job?/MAIN job?). One difference between these two questions in that the universe for usual hours all employed people (lfsr $94=1$ or lfsr94=2) while for hours last week is only employed currently at work (lfsr94=1). For respondents whose labor force status is employed, not at work (lfsr $=2$ ) the hours last week response is missing as they work zero hours last week and are out of the question's universe. The reason why these workers were absent from work last week are (proportion): vacation (53\%); illness (25\%); child care problems, family or personal problems,
} 
hours means that the hours of work last week were less than the hours in the usual week - a positive difference means that hours in the usual week are less than hours last week. The null hypothesis to test is whether the difference between usual and last week hours is zero, and during the World Cup I expect these difference in hours of work to be negative. Hereafter, I will refer to this difference as the weekly working gap. Importantly, I concentrate on the worker's flexibility to change hours across weeks, and am unable to identify flexibility within weeks or days. Omitting the latter attenuates my results towards zero, as I am failing to capture another dimension of schedule flexibility. Further, I am unable to make any statement about changes in total hours worked over the long run due to the World Cup, or any change in the worker's productivity.

Figure I and Figure II show the weekly working gap for 48 periods of time between 1994 and 2007 . Figure I refers to salary paid workers, and Figure II refers to hourly paid workers. Each time period is composed as follows: Period 1 contains observations surveyed during February(t), March(t) and April(t); Period 2 contains observations surveyed during May(t), June (t) and July(t); Period 3 contains observations from the August(t), September(t), and October(t) surveys; and Period 4 from the November $(\mathrm{t})$, December $(\mathrm{t})$ and January $(\mathrm{t}+1)$ surveys ${ }^{3}$ Periods when the World Cup is being played are highlighted in red and a dashed line marks all summers. The data in these figures highlight three facts: First, differences in hours of work between last weeks hours and a usual weeks hours tend to be negative, this is not surprising as workers tend to take days off, holidays, sick leave and vacation. Figure 1 also shows

paternity/maternity leave (12\%); all other (10\%). As these workers worked zero hours last week, I change the value of hours last week accordingly.

${ }^{3}$ In these figures I collapse the data into periods of three months just to facilitate the visual representation of the data, in the rest of the paper each period of time is one calandar month. 
that American workers do tend to work less hours last week on average during the World Cup than at other periods, but these differences do not seem much greater than differences in other June/July periods. Finally, these data show that the variance in differences between last week and usual hours is greater among salaried paid workers than among hourly paid workers which is not surprising given that salaried paid workers have more discretion over their hours of work in the short run than hourly paid workers do (Bureau of Labor Statistics, 2005).

The sample in this paper includes all employed males and females living in the United States surveyed in the CPS between 1994 and 2007, notice that the sample includes both foreign and native born workers. During this time four World Cups were played: USA 1994, France 1998, Korea-Japan 2002 and Germany $2006^{4}$. I restrict teachers and professors from the sample, as they are likely to change their working routine during the summers. I also drop from the sample agricultural workers. To control for outliers, I drop observations whose weekly working gap is greater than the 99th percentile and observations that are smaller than the 1st percentile. I also drop all observations whose hourly wage is smaller than $\$ 2.00$. All monetary units are in real dollars where the base period is January 1994. Basic summary statistics are presented in Table 2, the first column presents means for observations surveyed in months other than a World Cup month and the second column presents means for observations surveyed in months during the World Cup. The top panel presents means for all observations in the sample, and the bottom panel presents observations for workers who are salary paid. When analyzing the complete sample there are two important points to note in these raw estimates: first, usual hours worked are 0.19

\footnotetext{
${ }^{4}$ The results are robust to selecting only males, and robust to the inclusion of the 1994 World Cup or not
} 
(12 minutes) hours greater when the World Cup is at play than during other months while hours worked last week are shorter during World Cup months by 0.33 hours (18 minutes) - this is most likely because the World Cup is played during summers. Second, the proportion of employed workers who did not work last week is greater during the World Cup months as well and this difference is 1.4 percentage points. If I restrict the sample exclusively to salary paid workers, usual hours of work are indistinguishable between World Cup and non-World Cup surveys, but the difference in hours worked last week is almost an hour worked shorter during the World Cup months. Importantly, the proportion of employed workers reporting zero hours last week is almost twice as big during World Cup months than at other times.

To further explore these differences among salary paid workers between World Cup and non-World Cup summers, Table 3 presents the reason why last week hours are less than usual hours on each row, and the proportion workers whose last week hours are less than their usual workweek in the first two columns and the weekly working gap in the last two columns. Notice that this the sample in this table is restricted to salary paid workers surveyed exclusively in June or July. The results in this table suggest the following: first, although the same proportion of workers take time off due to holidays or vacations during summers with a World Cup and summers without, the working hours gap is greater during summers when the World Cup is played. Second, a greater proportion of workers reported less hours last week than in the usual week during World Cup summers due to either illness or slack labor. This result is similar to Skogman-Thoursie's (2002) who shows that workers in Sweden are more likely to report sick on the Monday after the Calgary Winter Olympic Games and the skiing cross country championships. 


\section{The FIFA World Cup}

Recently, economists have paid some attention to the World Cup. For example, Dohmen et al (2006) use an opinion survey in Germany to argue that when the performance of the German national team improved in the 2006 World Cup, the economic sentiments and expectations of Germans improved, and each win is associated with even more positive sentiments and expectations. Similarly Edmans et al (2007), use a cross-section of countries to show that when a country's national team loses in the World Cup, the country's stock market will observe on average a loss of 64 basis points in the following trading day. Hagn and Maennig (2008) use the World Cup as a natural experiment to compare employment in German cities who hosted the 1974 World Cup, and those cities who don't, and they fail to find any evidence of employment effects due to hosting the World Cup. Finally and closer to this paper, Tucker (2008) uses the 2002 World Cup as an exogenous instrument to analyze the benefits of the introduction of a communication technology in a financial institution.

The FIFA Soccer World Cup is played every 4 years. All countries that are members of FIFA must qualify in regional tournaments to play in the final round where games are played in the host country over the span of a month. Until the 1998 World Cup the final round consisted of 24 teams, and since then the number of teams playing in the final round has increased to 32. For example the 2006 finals were played by 5 African teams, 4 Asian teams (including the Middle East), 1 team from Oceania, 4

teams from Central America, North America or the Caribbean, 4 teams from South America and 14 teams from Europe. These 32 teams are divided into 8 groups of 4. The top two teams in each group (16 total) qualify to the second round, where 
the tournament takes a format of direct elimination. The second round is followed by the quarterfinals (third round) which consist of every winner of the second round (8 in total). The winners from each quarterfinal play in the semifinals, and finally the grand final and third place match that are played a month after the tournament started.

Table 1 presents information on local times and dates in which games were played for each of the four World Cups covered by the sample. Importantly, note that even within World Cup years there is variation in the calendar dates that the World Cup is played, and hence the CPS will observe different stages of the World Cup in different years. In particular, USA 1994 was played from June 17 to July 17, and two CPS surveys capture World Cup games in these days. The June survey, whose reference week refers to the days 12-18, includes the inauguration and first round games and the July survey includes the semifinals, the third place game and the grand final. France 1998 was played from June 12 to July 10 and also includes observations on the June survey when the first round was played (reference week June 7 to June 13) and the July survey as the tournaments final took place on Sunday of the reference week (July 12 to July 18). In contrast, Korea-Japan was played from May 31 to June 30, and the June surveys reference week includes 23 first round games. Germany 2006 was played between June 9 and July 9, and the June survey includes first round games from the week of June 11-June 17 plus the final match which was played on Sunday of the July surveys reference week.

It is worth noting that during the time span this paper covers soccer has gained in popularity in the United States. The New York Times (2006) reports that the World Cup final match in 2006 reached 16.9 million viewers, and 11.9 of them saw it on 
ABC while 5 million did on Spanish speaking Univision. This is a $152 \%$ increment from the 2002 World Cup and 31\% increment from 1998. Also, viewership for the 2006 final match was higher than that year's NBA finals and almost on par with the NCAA tournament. But not only the final match saw increased viewership: the average viewership for ABC, ESPN and ESPN2 was 1.7 million, 2.3 million and 1.1 million respectively. For the 2006 World Cup 17 out of 20 ESPN's match telecasts reached a rating of 1.0 or better, and 7 reached 2.0 or better. In the 1998 World Cup only 7 match telecasts reached a rating of 1.0 and only 1 reached a rating of 2.0 or better.

The identification strategy on this paper assumes that FIFA's decision of where and when the World Cup is played is independent from the U.S. labor market. If the choice of host country is done to maximize television viewership in the U.S then using variation in the time at which games are televised in the U.S. fails to identify workers' decision between market hours and time spent watching the World $\mathrm{Cup}^{5}$. If such is the case, then it is conceivable that the World Cup games are scheduled at times that maximize viewership, and in the absence of those games American workers will consume other types of leisure anyway, and observed decreases of hours of work during the World Cup will be spurious. This seems unlikely: First, the World Cups host country is chosen 7 years in advance of each tournament by FIFAs executive committee. The host country is chosen by a single transferable vote system, and each candidate country must fulfill the requisite of not belonging to the regional federation that hosted any of the previous two World Cups . But even if the decision by FIFAs executive committee is made by forecasting the best time to maximize U.S.

\footnotetext{
${ }^{5}$ This may be true for the 1994 U.S. World Cup, and the results in this paper are consistent with adding 1994 to the sample or not
} 
viewership, variation across different local time zones across different World Cups will identify the effect of the World Cup on hours of work as the World Cup will overlap with the workday in some parts of the U.S. and not in other parts. Further, given the length of one month that the World Cup lasts, I am assured that the CPS monthly survey will contain observations which were surveyed during a World Cup every four years.

\section{Empirical Strategy}

The empirical strategy in this paper consists of comparing the difference between hours of work last week and usual hours of work - heuristically this is similar to a matched pairs estimation where we observe for the same observations hours during the World Cup (hours last week) and hours at other times (usual hours of work). Specifically I estimate the following equation

$$
G_{i y t}=\gamma W C_{i y t}+x_{i y t}^{\prime} \theta+\epsilon_{i y t}
$$

where $G_{i y t}$ represents the gap between last week and usual hours, $W C_{\text {iyt }}$ is an indicator variable that takes a value of one during a World Cup month, and zero otherwise; $x_{i y t}^{\prime}$ is a vector of demographic characteristics that may or may not vary with time (age, age squared, education, state, year dummies and occupation fixed effects). The subscript $i$ represents each worker, $y$ represents each year and $t$ represents each month. The parameter of interest is $\gamma$ which represents the change in hours of work during the World Cup, $\gamma<0$ means that hours last week are shorter than usual hours in the main job. Equation 1 will estimate $\gamma$ consistently as long as 
$\operatorname{cov}\left(W C_{i y t}, \epsilon_{i y t}\right)=0$ which is an implausible assumption. As suggested in Figure 1 it is quite possible that hours of work are lower during the World Cup because this event takes place during the summer, and hours of work decrease during summers anyway even in the absence of the World Cup. Alternatively it may be that hours of work are shorter during the World Cup because of some idiosyncratic macroeconomic phenomenon during 1994, 1998, 2002 and 2006 - a time variant characteristic. To control for this I decompose $\epsilon_{i y t}=\mu_{t}+\nu_{y}+v_{i y t}$ where $\nu_{y}$ is a year specific component, $\mu_{t}$ is a month specific component and $v_{i y t}$ is a random variable assumed to have mean zero and iid across observations. Estimating equation 1 with year and month fixed effects estimates $\gamma$ consistently as long as differences in hours of work within each period of time are time invariant and $\operatorname{cov}\left(W C_{\text {iyt }}, v_{\text {iyt }}\right)=0$.

An alternative specification, that relaxes the time invariance assumption, is to take advantage of the scheduled times the World Cup is played. As mentioned above, the World Cup is played in a different country every four years, which generates variation in the time high profile games are broadcast in the United States. For example, during the USA 94 World Cup most games were played at 4:35 pm in the East Coast, which is 1:35 pm in the Pacific Coast. In the other hand, during the Korea-Japan 02 World Cup games that were played at 8:30 pm Asian Standard Time, were televised at 7:30 am on the United States' East Coast, and at 4:30 am in the Pacific Coast. As argued in the previous section, the variation in the choice of host country and therefore times games are televised in the United States is assumed to be exogenous because FIFA's Executive Committee chooses the country where the World Cup will be played arbitrarily. To take advantage of this variation I estimate the following equation: 


$$
G_{i y t}=\beta_{1} T 1_{i j t}+\beta_{2} T 2_{i j t}+\beta_{3} T 3_{i j t}+x_{i y t}^{\prime} \theta+\epsilon_{i y t}
$$

where $T 1_{i j t}$ equals one if most of the high profile games during the CPS survey week were televised in region $j$ between 12 am and 6 am and zero otherwise, $T 2_{i j t}$ takes a value of one if most of the high profile games during the CPS survey week were televised in region $j$ between 6 am and $12 \mathrm{pm}$, and $T 3_{i j t}$ takes a value of one if most of the high profile games during the CPS survey week were between $12 \mathrm{pm}$ and $6 \mathrm{pm}$ in region $j$. Again, for this specification I use the time when most of the high profile games were played during the reference week of the World Cup month and the time is marked with a star in Table 1. Under this strategy, note that none of the games were played between $6 \mathrm{pm}$ and 12 am in the different U.S. local times, and the omitted category in equation (2) is all observations surveyed in months when the World Cup is not played.

A third specification is:

$$
G_{i y t}=\delta_{1} M 1_{j y}+\delta_{2} M 2_{j y}+\delta_{3} M 3_{j y}+\delta_{4} M 4_{j y}++x_{i y t}^{\prime} \theta+\epsilon_{i y t}
$$

where $M 1_{j y}$ is the number of minutes World Cup games were broadcast live between 12 am and 6 am in region $j$ 's time zone during year $y$. Similarly $M 2_{j y}$ is the number of minutes games were broadcast live in region $j$ between 6 am and $12 \mathrm{pm}, M 3_{j y}$ is the number of minutes games were broadcast live in region $j$ live between $12 \mathrm{pm}$ and $6 \mathrm{pm}$, and $M 4_{j y}$ is the number of minutes games were broadcast live in region $j$. The estimates of $\delta_{1}-\delta_{4}$ are relative to changes in the hours of work during non-World Cup periods conditional on the variables in vector $x$. 
Importantly, as it may be possible that workers show up in their workplace during the World Cup, and they may take a break during the workday to follow the matches but fail to report different hours of work in the data, my results are likely to estimate a lower bound in these differences of the change in hours of work during the World $\operatorname{Cup}^{6}$.

\section{Results}

Unconditional estimates of equations 1, 2 and 3 are presented in Table 4, the top panel shows estimates from equation 1 , the second panel shows estimates from equation 2 , and the bottom panel shows estimates from equation 3. The first column presents estimates for all workers, second column estimates for hourly paid workers and the third column estimates for salary paid workers only. The first row in each panel represents the difference between actual hours and usual hours in times when the word is not in play. Across all specifications, this number is robust at values of 62 weekly minutes worked less for hourly paid workers and 58 weekly minutes less for salary paid workers. As in Figures I and II, it makes intuitive sense that these differences are negative as hours last week are likely zero sometimes because people take vacations, sick leave, and temporary separations from the job and as long as the separation is temporary and the job is still the respondents main job usual hours will be non-zero. The second row in the top panel presents unconditional estimates of $\gamma$ for equation 1, suggesting that all workers reduce work by 31 minutes per week

\footnotetext{
${ }^{6}$ While using television ratings for the World Cup is an attractive idea, I am unable to do this as weekly ratings by region are not available from Nielsen Media (conversation with Ms. Carly Litzenberg, Client Service Executive, The Nielsen Company) for the World Cups before 2002, thus using TV ratings will take away either the variation across space if I use all four World Cups, or across time if I use the regional data.
} 
during the World Cup before any type of controls are added, hourly paid workers reduce their paid work during the World Cup by 20 minutes per week, and salary paid workers decrease their market hours by almost fifty minutes per week.

The estimates for $\beta_{1}, \beta_{2}$ and $\beta_{3}$ in equation 2 are presented in the middle panel of Table 4. These estimates suggest that all American workers do not reduce their hours of work when games are played between 12 am and 6 am, they do reduce their hours by 28 minutes per week when games are played between 6 am and $12 \mathrm{pm}$, and by 33 minutes per week when games are played between $12 \mathrm{pm}$ and $6 \mathrm{pm}$. The magnitude of the estimates for salary paid workers suggest that any differences in market labor during the World Cup are greatest among this group: between 6 am and $12 \mathrm{pm}$ salary paid workers reduce their weekly hours by 43 minutes, while hourly paid workers reduce their weekly hours by 20 minutes. When games are between $12 \mathrm{pm}$ and $6 \mathrm{pm}$, salary paid workers reduce their weekly hours by 54 minutes, and hourly paid workers only by 21 minutes. Finally, rows 2, 3, 4 and 5 in the bottom panel show the estimates of $\delta_{1}, \delta_{2}, \delta_{3}$ and $\delta_{4}$ when the explanatory variable is the number of minutes a World Cup game was being broadcast at different time zones. Note that before controlling for other demographic characteristics, and concentrating on the salary paid sample, each minute a game is being broadcast suggest reductions of the hours gap by 0.05 minutes, 0.02 minutes and 0.26 minutes at $6 \mathrm{am}-12 \mathrm{pm}, 12 \mathrm{pm}$ $6 \mathrm{pm}$, and $6 \mathrm{pm}-12 \mathrm{am}$ respectively. The unusually high estimate for the $6 \mathrm{pm}-12 \mathrm{am}$ is due to the U.S. World Cup in 1994, when the games were played on TV's primetime, where not working due to vacation is more common. Again, the estimates in Table 4 are before any demographic controls are added, and due to the fact the World Cup is played during summers, these estimates confound the effect that the World Cup 
has on the weekly work schedule and the effect that vacations have on the weekly work schedules. Perhaps the one striking feature of this table is the difference in the World Cup coefficient's estimates between hourly and salary pay, especially as the last week-usual hours estimate which capture the hourly gap in non-World Cup periods is relatively close across the different pay groups. To compare estimates of changes in the workweek due to the World Cup within each month and controlling for other demographic characteristics, I turn to Tables 5, 6 and 7.

Table 5 presents ordinary least squares estimates for $\gamma$ when controls are added to equation 1. The first column presents estimates for all workers and includes controls for education, age, age squared, state, month fixed effects, and year fixed effects. The second column presents estimates for all workers and include occupation-year cross product fixed effects. The third and fourth columns present estimates for hourly paid workers, with and without occupation-year fixed effects respectively. The last two columns replicate the same, but for salary paid workers. The estimates across these specifications suggest that even after controlling for month and year fixed effects American workers reduce their number of weekly hours of work during the World Cup, and that this is mostly due to salary paid workers. For example, column 2 suggests that after controlling for observable characteristics all American workers reduce their hours of work by an average of 9 weekly minutes during the World Cup. When the sample is restricted to hourly paid workers the estimates are not statistically different than zero. When the sample is restricted to salary paid workers and include all controls, the change in hours of work during the World Cup is 28 minutes less. Again, these results highlight the importance of time-pay method on a worker's schedule flexibility, where salary paid workers exhibit more flexibility than 
hourly paid.

Table 6 presents estimates for equation 2, again using occupation-year fixed effects in the even numbered columns. The results in column 2 suggest that after controlling for demographic characteristics workers do not change their hours of work if the games are between 12 am and 6 am, but if games are between 6 am and 12 pm workers supply on average a little bit more than 15 minutes per week, and if games are between 12 $\mathrm{pm}$ and $6 \mathrm{pm}$ workers supply on average 8 minutes less per week. None of these estimates is statistically significant different than zero at the $5 \%$ confidence level, but the last two are at the $10 \%$ confidence level. Again, and as in Table 5, there are stark contrasts between hourly and salary paid workers, as the bulk of the changes in weekly hours of work are concentrated among the latter. That is, in column six, where I restrict the sample to salary paid workers, I find that when games are between 6 am and $12 \mathrm{pm}$ the hours of work decrease by more than 32 weekly minutes, and when games are between $12 \mathrm{pm}$ and $6 \mathrm{pm}$ the hours of work decrease by 28 weekly minutes. These estimates do not seem out of line, and make intuitive sense, as they suggest that one out of three salary paid American workers watch a World Cup game every week when the World Cup overlaps with the work day.

Table 7 presents estimates of equation 3, and they indicate the change in weekly minutes of work during the World Cup for each extra minute a game is played in each time slot. The results suggest that after controlling for demographic characteristics as well as year-occupation fixed effects, weekly minutes of work among all workers decrease by $\frac{2}{100}$ for each extra minute when games are broadcast between 6 am and $12 \mathrm{pm}$. If the sample is restricted to salary paid workers then weekly minutes of work during the World Cup decrease by $\frac{3}{100}$ of a minute during 6 am and $12 \mathrm{pm}$. These 
estimates are not different to those in Table 5 above, if one considers that the average World Cup week has approximately 10 games or 15 weekly hours in the 6 am to $12 \mathrm{pm}$ time slot, then 900 minutes $\times \frac{3}{100}$ equals 27 weekly minutes on average. Unlike Table 6 , the estimates for matches played between $12 \mathrm{pm}$ and $6 \mathrm{pm}$ are not statistically significant different than zero. This difference is mostly due to the definitions of $\mathrm{T} 1$, T2, and T3 where most of the games after $6 \mathrm{pm}$ in the USA 94 World Cup fell in the $12 \mathrm{pm}$ to $6 \mathrm{pm}$ category, as 4:35 pm was the most common match time and hence T2 got a value of one. Also, the point estimates in this table for games played between $6 \mathrm{pm}$ and $12 \mathrm{am}$ are big in magnitude, but measured with high standard errors, yet once month fixed effects are added these estimates attenuate significantly from those in Table 4 .

Table 8 estimates equation 1 for different subgroups (and their complements) of salary paid workers and they include year-occupation fixed effects: males, females, immigrants, hispanics, college graduates, married workers and workers with 35 or less years of age. If one concentrates on the point estimates, these estimates can be compared with a baseline for all salary paid workers of -28 weekly minutes in column 6 from Table 4. Not surprisingly males reduce their hours of work more than females during the World Cup, immigrants tend to reduce their hours more than native workers, and so do Hispanic workers. Surprisingly college graduates tend to reduce their hours more than workers with less education, that is they reduce their hours of work by more than 30 minutes (again, this is after all controls are added, including month and year fixed effects). Similarly, single or divorced workers reduce their hours more than married workers. Finally, young salary paid workers reduce their hours more than older workers do, by approximately more than 30 minutes. 
These differences should be taken with caution and rather as supporting evidence of the results in Tables 5, 6 and 7, as I am only comparing point estimates. Because of the small samples that result from breaking up the sample it is hard to make any inference across estimates based on the relatively high standard errors.

Finally, it is not clear whether wages should be included in equations 1 and 2, as wages may determine changes in the hours of work during the World Cup, and preferences for leisure may determine jointly the number of hours of work and wages for a given worker. Furthermore, when using CPS data wages are calculated by dividing usual weekly earnings over usual weekly hours of work, and the denominator of the explanatory variable will also be part of the response variable if wages are added to equation 1. Nevertheless, and assuming that I can identify the role that wages have on the gap between hours last week and usual hours, I estimate equation 1 to include up to a quartic term in log wages, plus interactions between the World Cup variables and log wages up to a quartic term ${ }^{7}$. The results are presented in Figure III which shows the estimated gap for equation 1 for salary and hourly paid workers and as in Table 4, again and as in Table 4 the bulk of the differences are concentrated among salary paid workers. Importantly, as we move across the distribution of wages from lowest earners to highest earners the difference in the weekly hours gap between observations surveyed during the World Cup and all other observations attenuates. That is salary paid American workers at the bottom of the distribution work on average one hour less during the World Cup, and this difference attenuates to thirty minutes for salary workers in the second quantile, and it continues diminishing as

\footnotetext{
${ }^{7}$ As usual hours enters in the left side of the equation with a negative sign and in the denominator on the right side of the equation, my intuition is that a higher hourly wage due to relatively low usual hours will bias the estimate of $\gamma$ towards zero as higher earnings will be associated with longer last week worked hours
} 
we move to the right of the distribution. This result is consistent with Aguiar and Hurst (2008) who show that low earners are more likeley to consume leisure than high earners. Importantly, and different to Aguiar and Hurst's finding, the relationship is concave and differences between usual and last week hours increase as we move from the fourth quartile to the highest earners. ${ }^{8}$.

\section{Discussion}

In this section I do different robustness checks to test whether the relationship that the coefficients discussed above are spurious, and they may be capturing some other event or phenomena that is unobserved in the data. The first exercise I do consists on extending equation 1 to add a dummy variable for the months before and after each World Cup. Specifically, I estimate the following equation for salaried workers exclusively:

$$
G_{i y t}=\lambda_{B} B_{i y t}+\lambda_{W C} W C_{i y t}+\lambda_{A} A_{i y t}+x_{i y t}^{\prime} \theta+\epsilon_{i y t}
$$

where $B_{\text {iyt }}$ represents a dummy variable that takes a value of one if the observation was surveyed in the month before the World Cup started, and $A_{\text {iyt }}$ represents a dummy variable that takes a value of 1 if the observation was surveyed in the month after the World Cup. If my results above are capturing some unobserved phenomenon then it may be that $\lambda_{B} \neq 0, \lambda_{W C} \neq 0$ and $\lambda_{A} \neq 0$. Note that if salaried workers have a contract with their employers that specifies a fixed number of hours of work in a set period of time, as suggested by the results in Conolly (2008), then it is possible that

\footnotetext{
${ }^{8} \mathrm{~A}$ similar exercise for equation 2 estimates a similar relationship, but the estimated differences between World Cup and other periods in the 6 am to $12 \mathrm{pm}$ time slot, and the $12 \mathrm{pm}$ to $6 \mathrm{pm}$ time slot are only statistically significant different from zero at the $10 \%$ confidence level.
} 
due to the World $\operatorname{Cup} \lambda_{B}>0, \lambda_{A}>0$, or $\lambda_{B}+\lambda_{A}>0$. If this is the case, then it must be that reductions of hours of work during the World Cup will be accompanied by increases in hours of work in the periods before or after the World Cup. This last point is difficult to prove, as inter-temporal substitution of hours of work is more likely within a week or even within a month, and not across months. Estimates for equation (4) are presented in the top panel of Table 9, the first column presents unconditional estimates and the second columns includes estimates when all demographic controls are added. Importantly, the estimates of $\lambda_{B}$ and $\lambda_{A}$ are zero, while the estimate of $\lambda_{w c}$ is similar to the estimate of $\gamma$ in Table 4. Similarly, I estimate whether changes in labor supply during the World Cup are compensated with changes in the hours of work in the months after and before the World Cup across different times when the World Cup is played. To do so I estimate the following extension of equation (2) for salaried workers:

$$
G_{i y t}=\sum_{k=1,2,3}\left(\pi_{k}^{B} B T k_{i y t}+\pi_{k}^{W C} W C T k_{i y t}+\pi_{k}^{A} A T k_{i y t}\right)+x_{i y t}^{\prime} \theta+\epsilon_{i y t}
$$

The interpretation of equation (6) is analogous to equation (2) and $B T 1_{\text {iyt }}$ takes a value of one if the observation was surveyed during the month before a World Cup, in a time zone where most of the matches were played between 12 am and 6 am local time; $W C T 1_{\text {iyt }}$ takes a value of one if the observation was surveyed during the month when the World Cup was played, in a time zone where most of the games were between 12 am and 6 am local time; $A T 1_{\text {iyt }}$ takes a value of one if the observation was surveyed during the month after a World Cup, in a time zone where most of the matches were played between 12 am and 6 am local time. Similarly $B T 2_{i y t}, W C T 2_{i} y t$ , $A T 2_{\text {iyt }}$ are defined for World Cups when games are played between 6 am and $12 \mathrm{pm}$ 
local time, and $B T 3_{i y t}, W C T 3_{i y t}, A T 3_{i y t}$ are defined for World Cup when games are played $12 \mathrm{pm}$ and $6 \mathrm{pm}$. The estimates are presented in the bottom panel of Table 9 . Again, the estimates for months before and after the World Cup are zero once that demographic controls are added. These results suggest that whatever is driving the reduction in hours of work during the World Cup is absent in the months before or after the World Cup is played.

Another robustness check to test whether the results in this paper are spurious is to test whether randomly chosen month-year combinations can replicate the results above. To do this I randomly choose 4 pairs on month-year combinations -- recall there are four World Cups periods in the sample -- and I generate the indicator variable $N W C--$ Not World Cup - - which takes a value of one if the observation is surveyed in a chosen year-month combination. I then estimate the following equation analogous to equation 1 :

$$
G_{i y t}=\psi N W C_{i y t}+x_{i y t}^{\prime} \theta+\epsilon_{i y t}
$$

and I replicate this exercise five hundred times. That is, I randomly generate 500 placebo World Cup experiments where the month and the year are randomly selected. Figure IV presents the histogram of the 500 different coefficients $\psi$ estimated in this exercise. Note hat the average mean of these coefficients is zero, further note that only $19 \%$ of these coefficients are statistically significant smaller than zero (one sided test), that only $5 \%$ of these coefficients fall to the left of the upper bound of the $95 \%$ confidence interval of the estimate of $\gamma$ in equation 1, and that less than $2 \%$ of these coefficients have a baseline estimate of magnitude as big (in absolute value) as that 
of the estimate of $\gamma$ in equation $1^{9}$.

It is possible that the difference between the estimates of the coefficients in Figure IV and the estimates in Table 4 are due to the fact that the World Cup is played during summers (although in equations 1, 2 and 3 I control for month fixed effects and this should take care of it). To test this hypothesis, I replicate the above exercise but I constrained the survey month to be either June or July, and randomly choose four years (different than the World Cup years), in such a way that the new $N W C$ variable is composed of observations from four different June/July-year combinations. Again, I estimate equation 6 two hundred times and the histogram of estimates is presented in Figure V. The average mean of these estimates is 2.14 minutes (not statistically significant different than zero) more during the placebo June/July World Cup observations, than at other times. Only six of these estimates are statistically significant smaller than zero. None of these placebo estimates reaches the upper limit of the baseline estimate $95 \%$ confidence interval. This result is intuitive as what I am doing is comparing June/July from the World Cup, with all other June/July, and is suggestive that whatever is driving the results for July 1994, June 1998, June-July 2002 and June 2006 is different than all other summers.

\section{Summary}

In today's labor market, workers benefit from having some flexibility in their work schedules, and the ability to periodically supply different hours of work at any given week than during the usual week will result in higher utility for the worker. In this

\footnotetext{
${ }^{9}$ Interestingly, 6 of the 9 estimates with a coefficient of magnitude -28 or smaller include the survey week of January, 1996 when the Atlantic Coast lived one of the worst blizzards ever recorded. While in January $19950.4 \%$ of salaried paid workers reported an absence for work due to weather and 2.0\% did in January 1997, 12.0\% did in January 1996.
} 
paper I use the natural variation that arises from the FIFA World Cup to explore the flexibility of the schedule of hours of work of American workers. The FIFA soccer World Cup presents a good natural experiment to test workers' schedule flexibility and take advantage of three exogenous sources of variation: the place where the World Cup is played which determines that the games will be televised in the United States at different hours during the day, differences in the times games are broadcast in different time zones, and the fact that the World Cup is played every four years which allows for inter-annual comparisons. I hypothesize that American workers are likely to reduce their hours of work when the timing of the games' live broadcast in the U.S. overlap with their market labor.

My results suggest that, after controlling for demographic characteristics, year and month fixed effects, American workers supply nine minutes of work less during the World Cup, a result that indicates that 1 in 10 American workers watch a weekly game. My results also show that the magnitude of these estimates is greater among salary paid workers, who reduce their hours of work on average by half an hour per week, this indicates that roughly 1 in 3 of all salary paid workers watch a World Cup game per week. Importantly, I show that my estimates for males, immigrants and highly educated workers are greater than for their complement demographic groups. Further, my results do not present any evidence that reductions of hours of work during the World Cup are accompanied with changes in the number of hours of work in the month before or after the World Cup, or that the results are driven by factors that are unobserved in the data. These results highlight the importance of pay frequency in a worker's schedule flexibility, as salaried paid workers have more discretion over the number of hours they work, highlighting an important difference between workers 
with different pay methods in the labor market.

\section{References}

[1] Aguiar, M., And Hurst, E. "Measuring leisure: The allocation of time over five decades". Quarterly Journal of Economics 122, 3 (2007), 969-1006.

[2] Alex Edmans, D. G., And Norli, O. "Sports sentiment and stock returns". Journal of Finance 62, 3 (2007), 1967-1998.

[3] BorJas, G. J. "The relationship between wages and weekly hours of work: The role of division bias". Journal of Human Resources 15, 3 (1980), 409-423.

[4] Bureau of Labor Statistics. "Workers on flexible and shift schedules in May 2004, USDL 05-1198", 2005. Mimeo.

[5] Coleman, M. T., And Pencavel, J. "Changes in work hours of male employees, 1940-1988". Industrial and Labor Relations Review 46, 2 (1993), 262-283.

[6] Coleman, M. T., And Pencavel, J. "Trends in market work behavior of women since 1940". Industrial and Labor Relations Review 46, 3 (1993), 653676.

[7] Conolly, M. "Here comes the rain again: Weather and the intertemporal substitution of leisure". Journal of Labor Economics 26, 1 (2008), 73-100.

[8] Costa, D. "The wage and the length of the work day: From the 1890s to 1991". Journal of Labor Economics 18, 1 (2000), 156-181. 
[9] Daniel C. Hamermesh, C. K. M., and Pocock, M. L. "Cues for timing and coordination: Latitude, letterman and longitude". Journal of Labor Economics 26, 2 (2008), 223-246.

[10] Gonzalez-Chepela, J. "On the price of recreation goods as a determinant of male labor supply". Journal of Labor Economics 25, 4 (2007), 795-824.

[11] Hagn, F., And Maning, W. "Employment effects of the Football World Cup 1974 in Germany". Labour Economics 15, 5 (2008), 1062-1075.

[12] Hamermesh, D. C. "12 million salary workers missing". Industrial and Labor Relations Review 55, 4 (2002), 549-566.

[13] Kuhn, P. J., And Lozano, F. A. "The expanding workweek? understanding trends in long work hours among US men 1979-2006". Journal of Labor Economics 26, 2 (2008), 311-344.

[14] Sandomil, R. "Cup ratings are up, but fans deserve better". New York Times (July 11, 2006).

[15] Skogman-Thoursie, P. "Reporting sick: Are sporting events contagious". Journal of Applied Econometrics 19, 3 (2004), 809-923.

[16] Thomas Dohmen, Armin Falk, D. H., And Sunde, U. "Seemingly irrelevant events affect economic perceptions and expectations: the FIFA World Cup 2006 as a natural experiment". IZA Working paper 2275 (2006).

[17] TuCKer, C. "Identifying formal and informal influence in technology adoption with network externalities". Management Science 54, 12 (2008), 2024-2038. 


\section{Figure I}

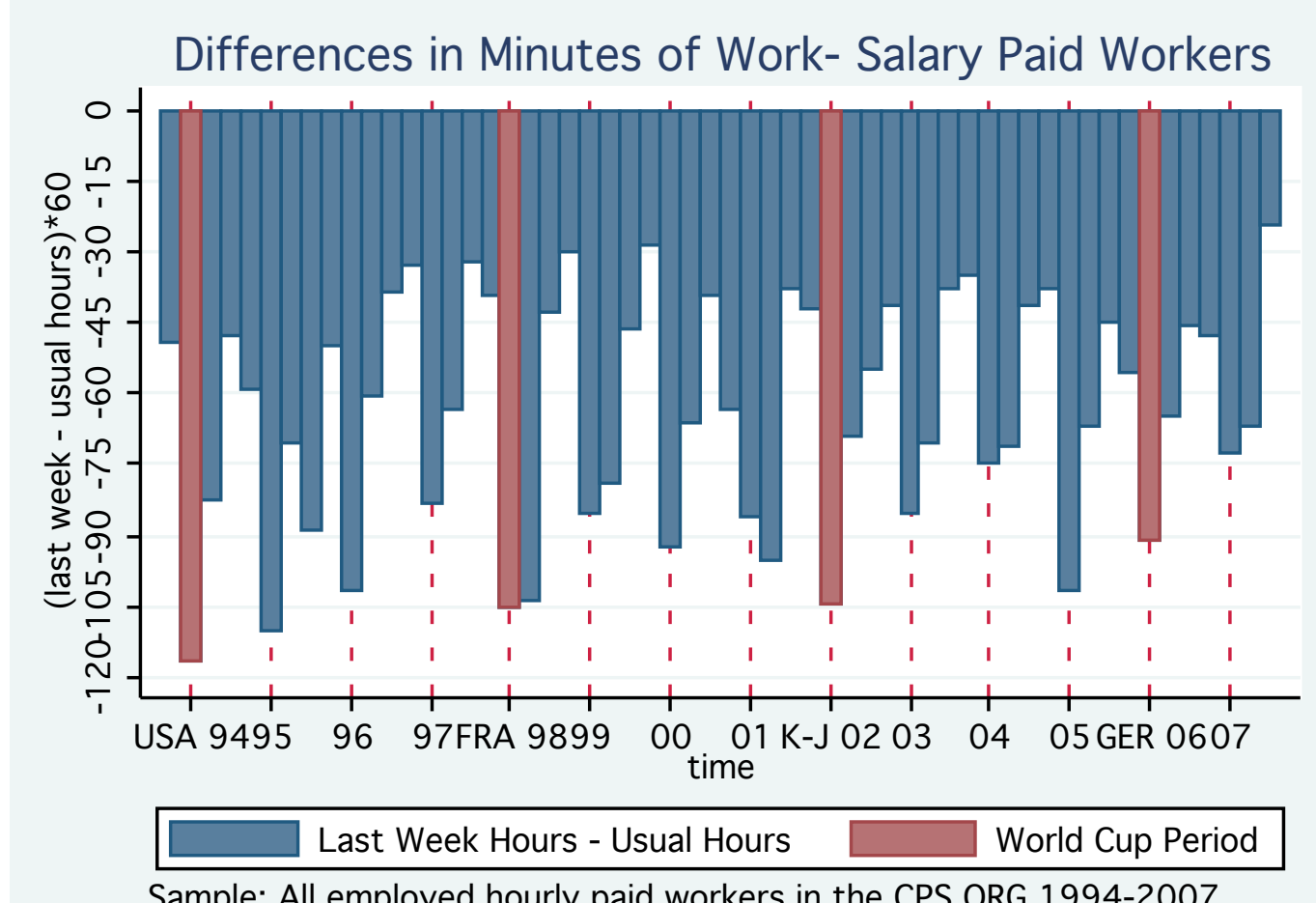




\section{Figure II}

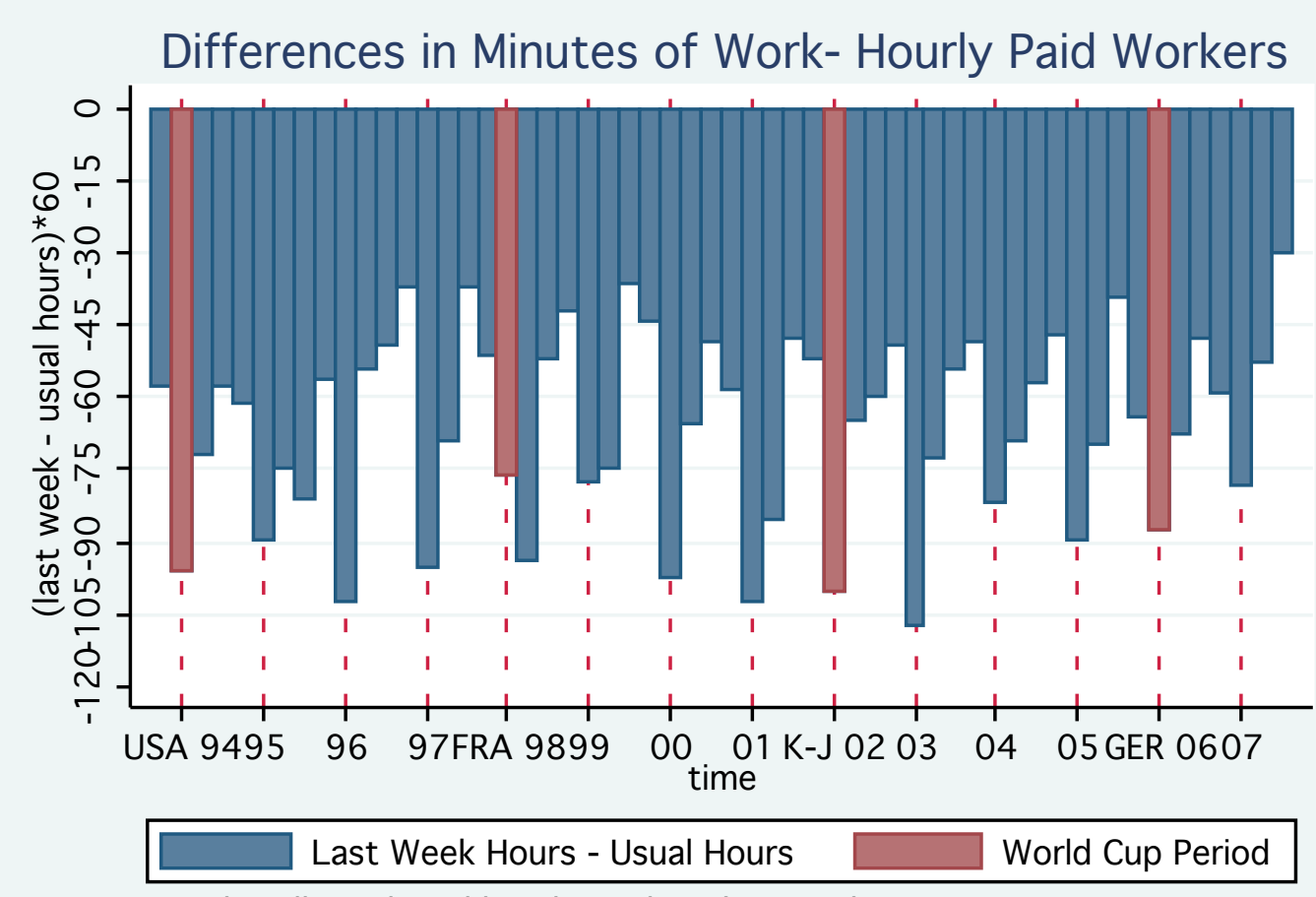

Sample: All employed hourly paid workers in the CPS ORG 1994-2007 


\section{Figure III}

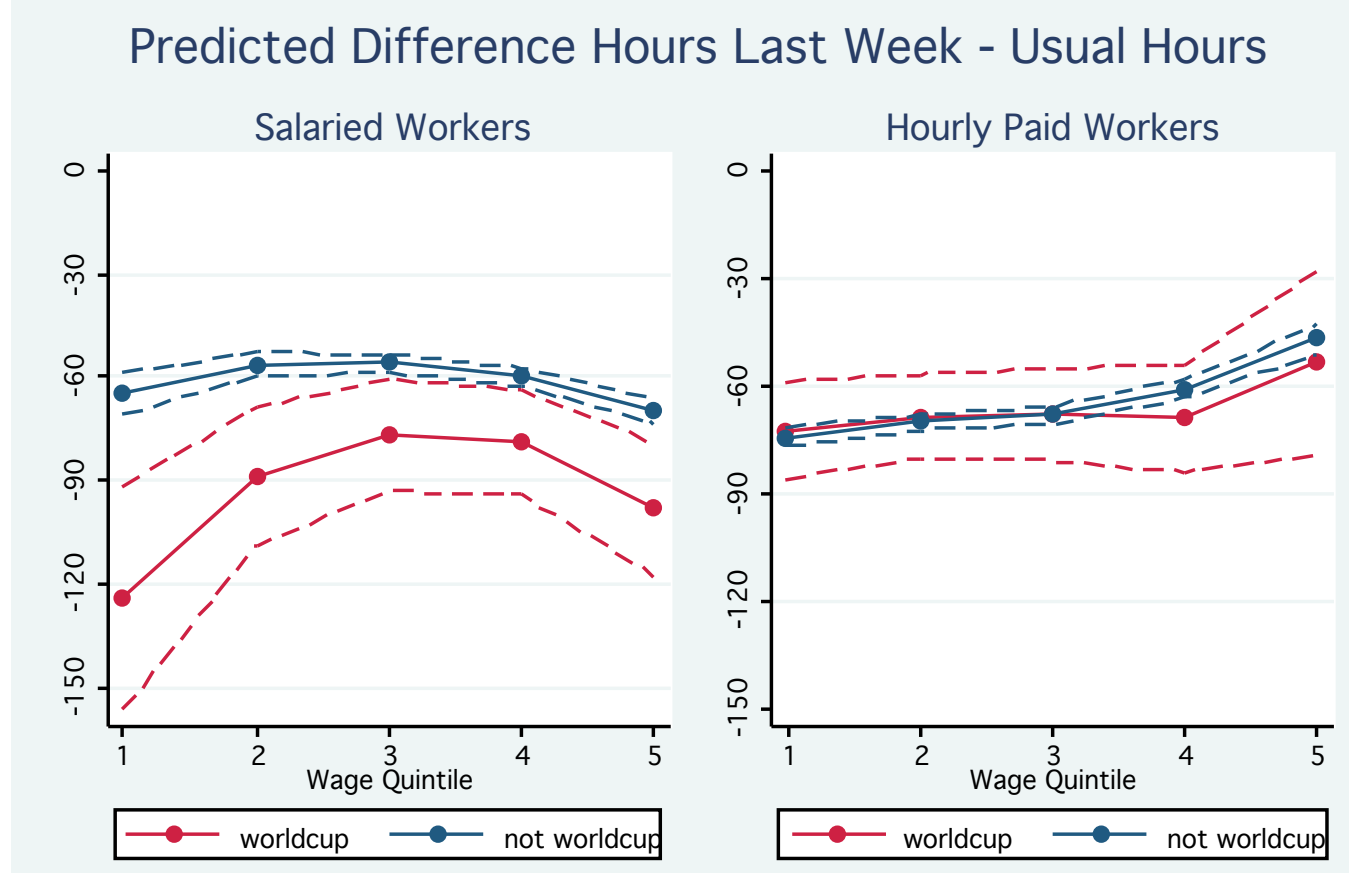

Dashed lines represent 95\% confidence intervals

Source: All employed workers in the CPS ORG 1994-2006 


\section{Figure IV}

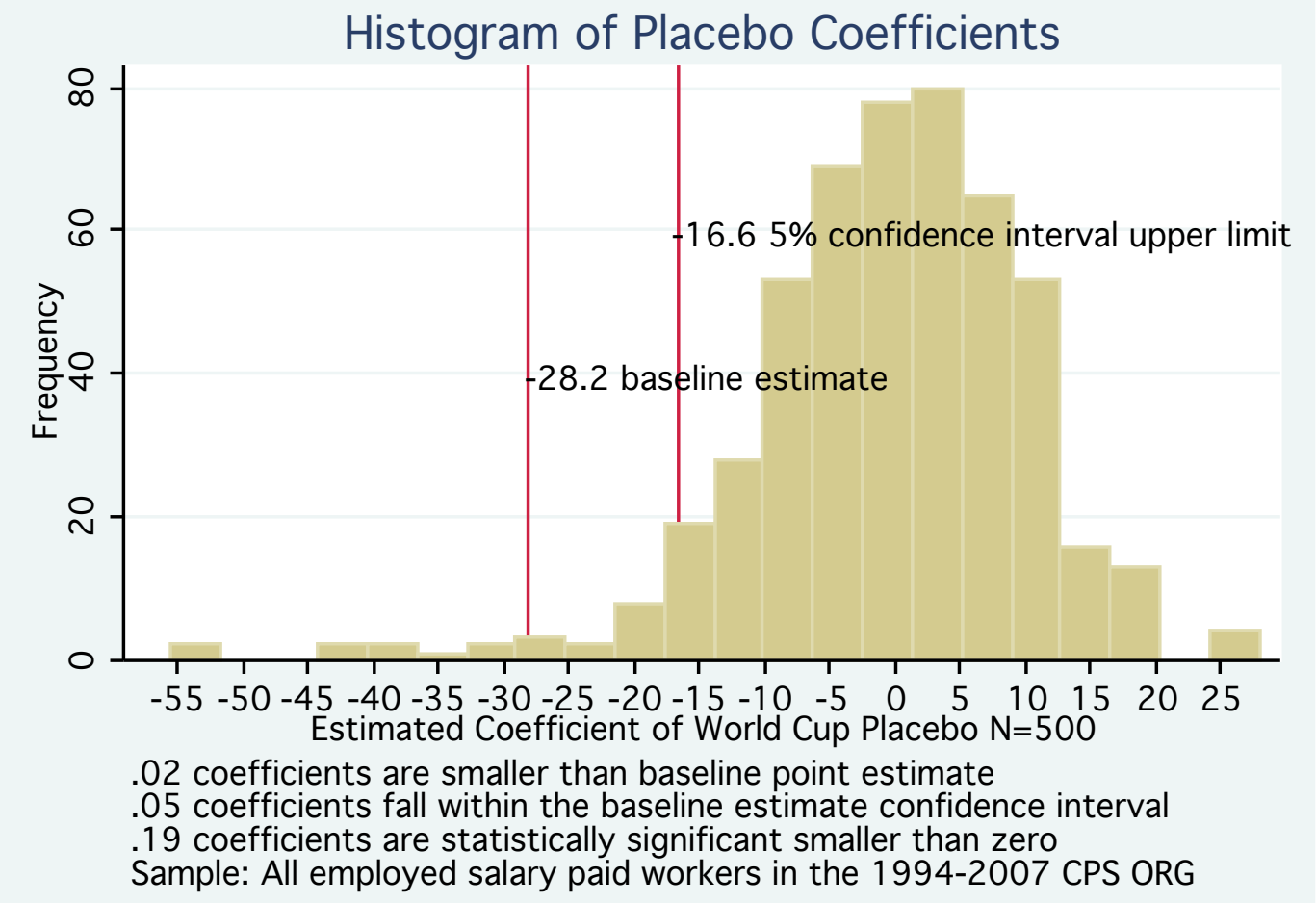




\section{Figure V}

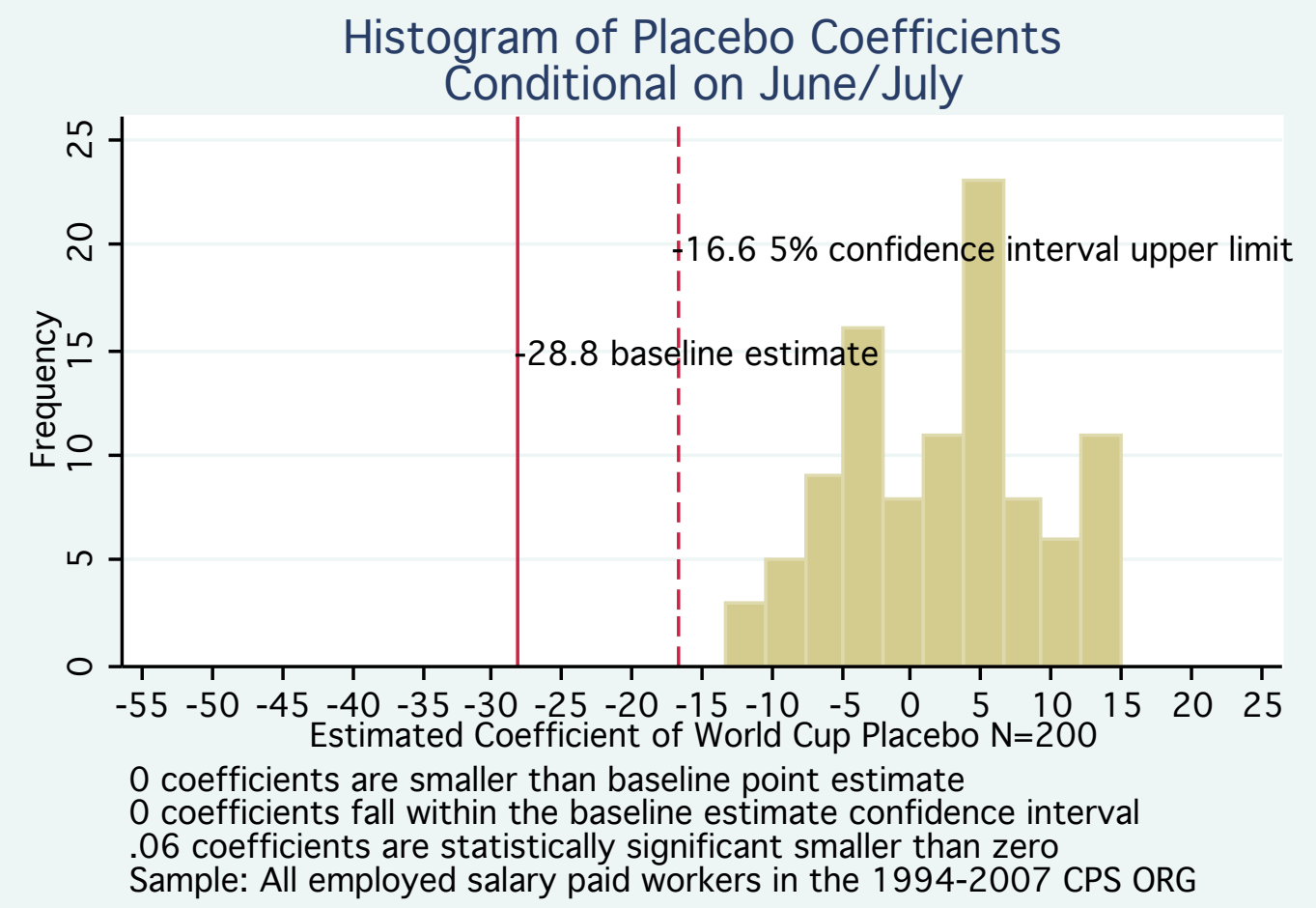


Table 1: Minutes Played in Each Time Zone During CPS Survey Week

\begin{tabular}{|c|c|c|c|c|}
\hline \multicolumn{5}{|l|}{ All World Cups } \\
\hline Time & EST & CST & MST & PST \\
\hline $12 \mathrm{am}-6 \mathrm{am}$ & 1260 & 1260 & 1530 & 1830 \\
\hline $6 \mathrm{am}-12 \mathrm{pm}$ & 1435 & 1945 & 1705 & 2190 \\
\hline $12 \mathrm{pm}-6 \mathrm{pm}$ & 2705 & 2270 & 2420 & 1380 \\
\hline $6 \mathrm{pm}-12 \mathrm{am}$ & 270 & 195 & 15 & 270 \\
\hline \multicolumn{5}{|c|}{ United States 1994: June 17 to July 17} \\
\hline $12 \mathrm{am}-6 \mathrm{am}$ & 0 & 0 & 0 & 0 \\
\hline $6 \mathrm{am}-12 \mathrm{pm}$ & 25 & 145 & 175 & 180 \\
\hline $12 \mathrm{pm}-6 \mathrm{pm}$ & $695^{*}$ & $650^{*}$ & $800^{*}$ & $810^{*}$ \\
\hline $6 \mathrm{pm}-12 \mathrm{am}$ & 270 & 195 & 15 & 0 \\
\hline \multicolumn{5}{|c|}{ France 1998: June 12 to July 10} \\
\hline $12 \mathrm{am}-6 \mathrm{am}$ & 0 & 0 & 0 & 30 \\
\hline $6 \mathrm{am}-12 \mathrm{pm}$ & 180 & 360 & 360 & 330 \\
\hline $12 \mathrm{pm}-6 \mathrm{pm}$ & $540^{*}$ & $360^{*}$ & $360^{*}$ & $360^{*}$ \\
\hline $6 \mathrm{pm}-12 \mathrm{am}$ & 0 & 0 & 0 & 0 \\
\hline \multicolumn{5}{|c|}{ Korea-Japan 2002: May 31 to June 30} \\
\hline $12 \mathrm{am}-6 \mathrm{am}$ & 1260 & 1260 & $1530^{*}$ & $1800^{*}$ \\
\hline $6 \mathrm{am}-12 \mathrm{pm}$ & $810^{*}$ & $810^{*}$ & 540 & 0 \\
\hline $12 \mathrm{pm}-6 \mathrm{pm}$ & 0 & 0 & 0 & 0 \\
\hline $6 \mathrm{pm}-12 \mathrm{am}$ & 0 & 0 & 0 & 270 \\
\hline \multicolumn{5}{|c|}{ Germany 2006: June 9 to July 9} \\
\hline $12 \mathrm{am}-6 \mathrm{am}$ & 0 & 0 & 0 & 0 \\
\hline $6 \mathrm{am}-12 \mathrm{pm}$ & 420 & 630 & 630 & $1680^{*}$ \\
\hline $12 \mathrm{pm}-6 \mathrm{pm}$ & $1470^{*}$ & $1260^{*}$ & $1260^{*}$ & 210 \\
\hline $6 \mathrm{pm}-12 \mathrm{am}$ & 0 & 0 & 0 & 270 \\
\hline
\end{tabular}

Source: FIFA.com 
Table 2: Summary Statistics: Weekly Hours of Work

\begin{tabular}{lcc}
\hline \hline & $(1)$ & $(2)$ \\
& Not World Cup & World Cup \\
\hline Usual hours & 39.031 & 39.223 \\
& $(0.007)$ & $(0.045)$ \\
Hours last week & 38.020 & 37.688 \\
& $(0.010)$ & $(0.063)$ \\
Not working — employed & 0.028 & 0.042 \\
& $(0.000)$ & $(0.001)$ \\
Proportion salary paid & 0.368 & 0.364 \\
& $(0.000)$ & $(0.002)$ \\
$\mathrm{N}$ & $1,821,466$ & 46,309 \\
\hline \multicolumn{3}{c}{ Conditional on being salary paid } \\
\hline Usual hours & 42.869 & 42.863 \\
& $(0.011)$ & $(0.072)$ \\
Hours last week & 41.901 & 41.047 \\
\multirow{2}{*}{ Not working - employed } & $(0.015)$ & $(0.105)$ \\
& 0.021 & 0.039 \\
$\mathrm{~N}$ & $(0.000)$ & $(0.001)$ \\
\hline \hline
\end{tabular}

Sample: All workers in the 1994-2007 CPS ORG

Standard errors in parentheses. 
Table 3: Differences in Weekly Hours of Work

\begin{tabular}{|c|c|c|c|c|}
\hline & $(1)$ & (2) & (3) & (4) \\
\hline & \multicolumn{2}{|c|}{ Proportion working less } & \multicolumn{2}{|c|}{ Change in minutes $\mid$ working less } \\
\hline & Not World Cup & World Cup & Not World Cup & World Cup \\
\hline \multirow{2}{*}{ Vacation-holiday } & 0.066 & 0.066 & -24.449 & $-25.806^{*}$ \\
\hline & $(0.001)$ & $(0.002)$ & $(0.166)$ & $(0.411)$ \\
\hline \multirow{2}{*}{ Childcare problems } & 0.007 & 0.007 & -22.583 & -22.158 \\
\hline & $(0.000)$ & $(0.001)$ & $(0.535)$ & $(1.267)$ \\
\hline \multirow{2}{*}{ Illness } & 0.012 & $0.016^{*}$ & -20.703 & -22.730 \\
\hline & $(0.000)$ & $(0.001)$ & $(0.391)$ & $(0.861)$ \\
\hline \multirow{2}{*}{ Slack work-labor disputes } & 0.003 & $0.004^{*}$ & -15.466 & -17.439 \\
\hline & $(0.000)$ & $(0.001)$ & $(0.603)$ & $(1.225)$ \\
\hline \multirow[t]{2}{*}{ Bad weather } & 0.001 & 0.000 & -16.952 & -11.317 \\
\hline & $(0.000)$ & $(0.000)$ & $(1.491)$ & $(2.244)$ \\
\hline \multirow[t]{2}{*}{ Other } & 0.005 & 0.006 & -22.314 & -23.024 \\
\hline & $(0.000)$ & $(0.001)$ & $(0.633)$ & $(1.507)$ \\
\hline $\mathrm{N}$ & 96,740 & 16,671 & & \\
\hline
\end{tabular}

Sample: All salary paid workers surveyed in June or July in the 1994-2007 CPS ORG. * Denotes World Cup estimate is statistically significant different from the non World Cup estimate at 95\% confidence level. Standard errors in parentheses. 
Table 4: OLS Minutes of Work on World Cup Unconditional Estimates

\begin{tabular}{|c|c|c|c|}
\hline & $\begin{array}{c}(1) \\
\text { All workers }\end{array}$ & $\begin{array}{c}(2) \\
\text { Hourly paid }\end{array}$ & $\begin{array}{c}(3) \\
\text { Salary paid }\end{array}$ \\
\hline \multicolumn{4}{|c|}{ (a) World Cup indicator variable } \\
\hline Last week - Usual hours & $\begin{array}{c}-60.644^{*} \\
(0.459)\end{array}$ & $\begin{array}{c}-62.139^{*} \\
(0.583)\end{array}$ & $\begin{array}{c}-58.074^{*} \\
(0.695)\end{array}$ \\
\hline During World Cup & $\begin{array}{c}-31.437^{*} \\
(3.398)\end{array}$ & $\begin{array}{c}-20.274^{*} \\
(4.101)\end{array}$ & $\begin{array}{c}-50.892^{*} \\
(5.194)\end{array}$ \\
\hline $\mathrm{N}$ & $1,867,775$ & $1,187,708$ & 680,067 \\
\hline \multicolumn{4}{|c|}{ (b) Most common time of game indicator variable } \\
\hline Last week - Usual hours & $\begin{array}{c}-60.644^{*} \\
(0.459)\end{array}$ & $\begin{array}{c}-62.139^{*} \\
(0.583)\end{array}$ & $\begin{array}{c}-58.074^{*} \\
(0.695)\end{array}$ \\
\hline World Cup match $0-6$ & $\begin{array}{l}-16.490 \\
(11.279)\end{array}$ & $\begin{array}{c}-9.735 \\
(14.656)\end{array}$ & $\begin{array}{l}-28.193 \\
(19.923)\end{array}$ \\
\hline World Cup match $6-12$ & $\begin{array}{c}-28.792^{*} \\
(7.614)\end{array}$ & $\begin{array}{c}-20.156^{*} \\
(9.877)\end{array}$ & $\begin{array}{l}-43.258^{*} \\
(10.481)\end{array}$ \\
\hline World Cup match $12-18$ & $\begin{array}{c}-33.223^{*} \\
(3.988)\end{array}$ & $\begin{array}{c}-21.049^{*} \\
(4.703)\end{array}$ & $\begin{array}{c}-54.698^{*} \\
(6.238)\end{array}$ \\
\hline $\mathrm{N}$ & $1,867,775$ & $1,187,708$ & 680,067 \\
\hline (c) Minutes played at each & me variable & & \\
\hline Last week - Usual hours & $\begin{array}{c}-60.704^{*} \\
(0.460)\end{array}$ & $\begin{array}{c}-62.161^{*} \\
(0.583)\end{array}$ & $\begin{array}{c}-58.202^{*} \\
(0.695)\end{array}$ \\
\hline Minutes $0-6$ & $\begin{array}{c}0.006 \\
(0.006)\end{array}$ & $\begin{array}{c}0.008 \\
(0.008)\end{array}$ & $\begin{array}{c}0.004 \\
(0.009)\end{array}$ \\
\hline Minutes $6-12$ & $\begin{array}{l}-0.034^{*} \\
(0.008)\end{array}$ & $\begin{array}{l}-0.027^{*} \\
(0.011)\end{array}$ & $\begin{array}{l}-0.046^{*} \\
(0.012)\end{array}$ \\
\hline Minutes $12-18$ & $\begin{array}{l}-0.006 \\
(0.005)\end{array}$ & $\begin{array}{c}0.002 \\
(0.007)\end{array}$ & $\begin{array}{l}-0.020^{*} \\
(0.008)\end{array}$ \\
\hline Minutes $18-24$ & $\begin{array}{c}-0.217^{*} \\
(0.034)\end{array}$ & $\begin{array}{c}-0.194^{*} \\
(0.041)\end{array}$ & $\begin{array}{l}-0.259^{*} \\
(0.055)\end{array}$ \\
\hline $\mathrm{N}$ & $1,867,775$ & $1,187,708$ & 680,067 \\
\hline
\end{tabular}

* Denotes statistically significant different to zero at 5\% confidence level.

Robust standard errors in parentheses clustered at PSU level.

Sample: All workers in the 1994-2007 CPS ORG. 
Table 5: OLS Minutes of Work on World Cup Conditional Estimates

\begin{tabular}{lcccccc}
\hline & $(1)$ & $(2)$ & \multicolumn{2}{c}{$(3)$} & $(4)$ & \multicolumn{2}{c}{$(5)$} & $(6)$ \\
& \multicolumn{2}{c}{ All workers } & \multicolumn{2}{c}{ Hourly paid } & \multicolumn{2}{c}{ Salary paid } \\
\hline World Cup Indicator & $-8.982^{*}$ & $-8.973^{*}$ & 2.207 & 1.968 & $-28.388^{*}$ & $-28.115^{*}$ \\
& $(3.732)$ & $(3.734)$ & $(4.566)$ & $(4.570)$ & $(5.793)$ & $(5.782)$ \\
Occ-Year Fixed Effects & No & Yes & No & Yes & No & Yes \\
Constant & $-16.392^{*}$ & -4.914 & $-18.930^{*}$ & -8.015 & -16.375 & 0.816 \\
& $(6.159)$ & $(5.998)$ & $(7.456)$ & $(7.214)$ & $(11.877)$ & $(11.707)$ \\
$\mathrm{R}^{2}$ & 0.006 & 0.007 & 0.005 & 0.007 & 0.008 & 0.010 \\
$\mathrm{~N}$ & $1,867,775$ & $1,867,775$ & $1,187,708$ & $1,187,708$ & 680,067 & 680,067 \\
\hline \hline
\end{tabular}

* Denotes statistically significant different than zero at $5 \%$ confidence level.

Robust standard errors in parentheses clustered at PSU level.

Sample: All workers in the 1994-2007 CPS ORG.

Other regressors included are month fixed effects, year fixed effects, state fixed effects, years of education, age, age squared hispanic, black, immigrant, marital status and female indicator. 
Table 6: OLS Minutes of Work on World Cup by Hour of Match

\begin{tabular}{lcccccc}
\hline \hline & $(1)$ & $(2)$ & \multicolumn{2}{c}{$(3)$} & $(4)$ & \multicolumn{2}{c}{$(5)$} & $(6)$ \\
& \multicolumn{2}{c}{ All workers } & \multicolumn{2}{c}{ Hourly paid } & \multicolumn{2}{c}{ Salary paid } \\
\hline World Cup match 0 -6 & -4.324 & -1.829 & 3.014 & 6.178 & -16.550 & -14.269 \\
& $(11.491)$ & $(11.600)$ & $(14.848)$ & $(14.898)$ & $(20.405)$ & $(20.583)$ \\
World Cup match $6-12$ & $-17.668^{*}$ & -15.471 & -8.168 & -5.660 & $-33.580^{*}$ & $-32.138^{*}$ \\
& $(7.805)$ & $(8.037)$ & $(10.115)$ & $(10.248)$ & $(10.781)$ & $(11.120)$ \\
World Cup match 12 -18 & $-11.036^{*}$ & -7.774 & 0.925 & 3.614 & $-32.118^{*}$ & $-27.973^{*}$ \\
& $(4.086)$ & $(4.196)$ & $(4.910)$ & $(5.074)$ & $(6.499)$ & $(6.658)$ \\
Occ-Year Fixed Effects & No & Yes & No & Yes & No & Yes \\
Constant & -6.770 & -4.906 & -10.230 & -8.017 & -5.081 & 0.859 \\
& $(5.839)$ & $(5.998)$ & $(7.045)$ & $(7.215)$ & $(11.550)$ & $(11.707)$ \\
$\mathrm{R}^{2}$ & 0.006 & 0.007 & 0.005 & 0.007 & 0.008 & 0.010 \\
$\mathrm{~N}$ & $1,867,775$ & $1,867,775$ & $1,187,708$ & $1,187,708$ & 680,067 & 680,067 \\
\hline \hline
\end{tabular}

* Denotes statistically significant at $5 \%$ confidence level.

Robust standard errors in parentheses clustered at PSU level.

Sample: All workers in the 1994-2007 CPS ORG.

Other regressors included are month fixed effects, year fixed effects, state fixed effects, years of education, age, age squared hispanic, black, immigrant, marital status and female indicator. 
Table 7: OLS Hours of Work on World Cup by Minutes Played in Survey Week

\begin{tabular}{|c|c|c|c|c|c|c|}
\hline & (1) & $(2)$ & $(3)$ & $(4)$ & $(5)$ & (6) \\
\hline & \multicolumn{2}{|c|}{ All workers } & \multicolumn{2}{|c|}{ Hourly paid } & \multicolumn{2}{|c|}{ Salary paid } \\
\hline \multirow[t]{2}{*}{ World Cup match $0-6$} & 0.004 & 0.004 & 0.007 & 0.007 & 0.000 & -0.001 \\
\hline & $(0.006)$ & $(0.006)$ & $(0.008)$ & $(0.008)$ & $(0.009)$ & $(0.010)$ \\
\hline \multirow[t]{2}{*}{ World Cup match $6-12$} & $-0.023^{*}$ & $-0.022^{*}$ & -0.017 & -0.015 & $-0.035^{*}$ & $-0.033^{*}$ \\
\hline & $(0.008)$ & $(0.008)$ & $(0.011)$ & $(0.011)$ & $(0.012)$ & $(0.012)$ \\
\hline \multirow[t]{2}{*}{ World Cup match $12-18$} & 0.004 & 0.005 & 0.012 & 0.013 & -0.010 & -0.009 \\
\hline & $(0.006)$ & $(0.006)$ & $(0.007)$ & $(0.007)$ & $(0.008)$ & $(0.009)$ \\
\hline \multirow[t]{2}{*}{ World Cup match $18-24$} & $-0.079^{*}$ & -0.050 & -0.064 & -0.037 & $-0.109^{*}$ & -0.073 \\
\hline & $(0.035)$ & $(0.036)$ & $(0.042)$ & $(0.043)$ & $(0.056)$ & $(0.057)$ \\
\hline Occ-Year Fixed Effects & No & Yes & No & Yes & No & Yes \\
\hline \multirow[t]{2}{*}{ Constant } & -6.835 & -4.968 & -10.315 & -8.081 & -5.080 & 0.838 \\
\hline & $(5.838)$ & $(5.998)$ & $(7.045)$ & $(7.213)$ & $(11.550)$ & $(11.708)$ \\
\hline $\mathrm{R}^{2}$ & 0.006 & 0.007 & 0.005 & 0.007 & 0.007 & 0.010 \\
\hline $\mathrm{N}$ & $1,867,775$ & $1,867,775$ & $1,187,708$ & $1,187,708$ & 680,067 & 680,067 \\
\hline
\end{tabular}

* Denotes statistically significant different than zero at $5 \%$ confidence level.

Robust standard errors in parentheses clustered at PSU level.

Sample: All workers in the 1994-2007 CPS ORG.

Other regressors included are month fixed effects, year fixed effects, state fixed effects, years of education, age, age squared hispanic, black, immigrant, marital status and female indicator. 


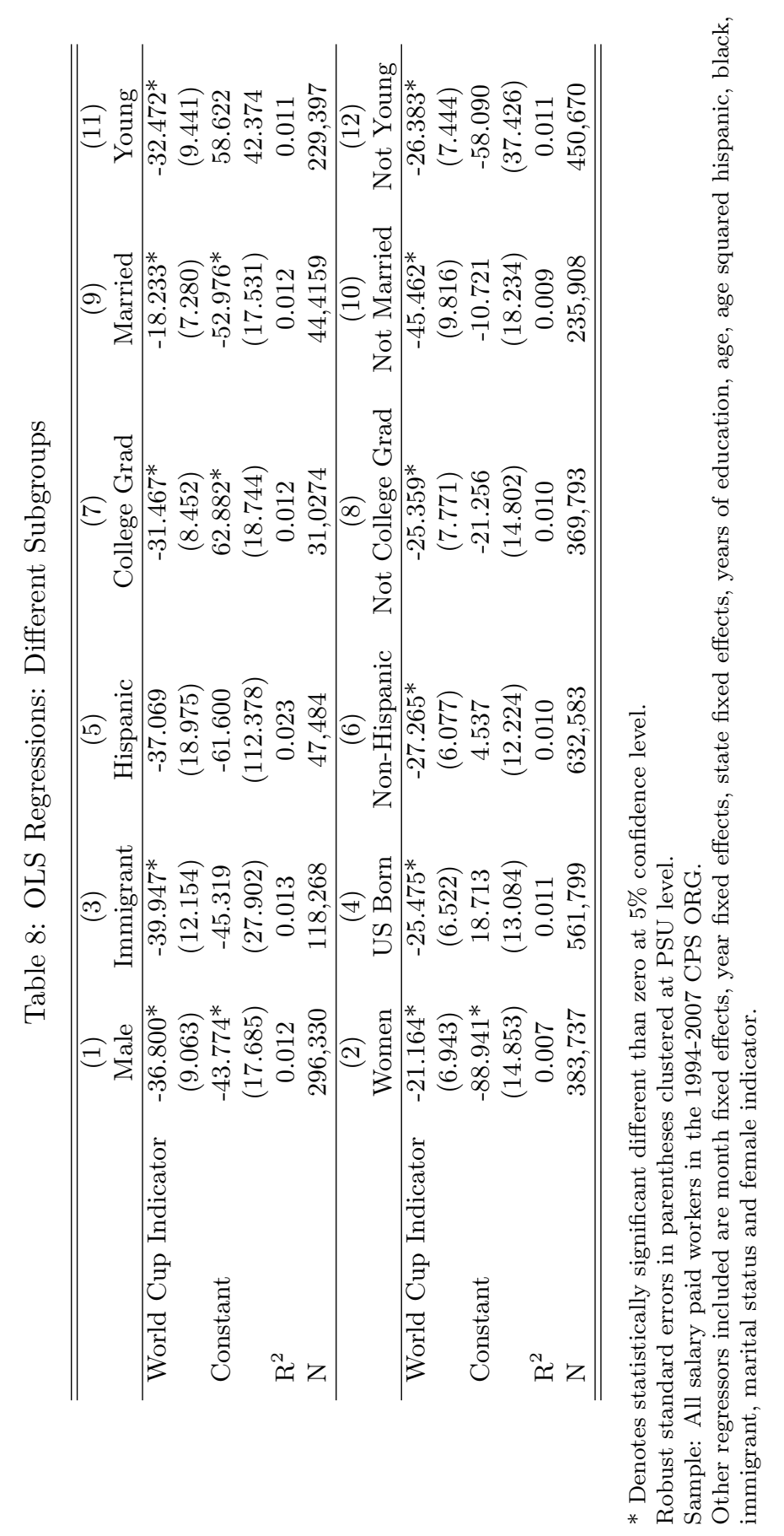


Table 9: OLS Hours of Work on World Cup, Before and After

\begin{tabular}{lcc}
\hline \hline & $(1)$ & $(2)$ \\
(a) World Cup indicator variable & & \\
\hline Month before World Cup & $14.305^{*}$ & 5.397 \\
& $(4.126)$ & $(4.830)$ \\
During World Cup & $-51.736^{*}$ & $-26.140^{*}$ \\
& $(5.201)$ & $(5.911)$ \\
Month after World Cup & $-50.442^{*}$ & 8.108 \\
& $(5.293)$ & $(5.950)$ \\
Controls & No & Yes \\
Occ-Year Fixed Effects & No & Yes \\
Constant & $-57.230^{*}$ & 0.827 \\
& $(0.712)$ & $(11.707)$ \\
$\mathrm{R}^{2}$ & 0.001 & 0.010 \\
$\mathrm{~N}$ & 680,067 & 680,067 \\
\hline (a) Most common time of game indicator & \\
\hline Month before WC match $0-6$ & 5.739 & -10.245 \\
& $(16.197)$ & $(17.142)$ \\
World Cup match $0-6$ & -29.037 & -14.023 \\
& $(19.924)$ & $(20.652)$ \\
Month after WC match $0-6$ & $-69.463^{*}$ & -12.885 \\
& $(20.131)$ & $(20.701)$ \\
Month before WC match $6-12$ & $17.428^{*}$ & -1.830 \\
& $(7.847)$ & $(8.721)$ \\
World Cup match $6-12$ & $-44.101^{*}$ & $-31.737^{*}$ \\
& $(10.481)$ & $(11.224)$ \\
Month after WC match $6-12$ & $-50.822^{*}$ & 3.923 \\
& $(11.073)$ & $(11.939)$ \\
Month before WC match $12-18$ & $13.993^{*}$ & 8.330 \\
& $(4.919)$ & $(5.528)$ \\
World Cup match 12 - 18 & $-55.542^{*}$ & $-25.263^{*}$ \\
Month after WC match 12 - 18 & $(6.245)$ & $(6.802)$ \\
& $-49.038^{*}$ & 10.673 \\
Controls & $(6.297)$ & $(6.792)$ \\
Occ-Year Fixed Effects & No & Yes \\
Constant & No & Yes \\
& $-57.230^{*}$ & 0.786 \\
N & $(0.712)$ & $(11.708)$ \\
\hline \hline & 0.001 & 0.010 \\
& 680,067 & 680,067 \\
\hline
\end{tabular}

* Denotes statistically significant different than zero at $5 \%$ confidence level.

Robust standard errors in parentheses clustered at PSU level.

Sample: All salary paid workers in the 1994-2007 CPS ORG.

Other regressors included are month fixed effects, year fixed effects, state fixed effects, years of education, age, age squared hispanic, black, immigrant, marital status and female indicator. 